\title{
Strategies for Selling Paid Content on Newspaper and Magazine Web Sites: An Empirical Analysis of Bundling and Splitting of News and Magazine Articles
}

\author{
Florian Stahl, Marc-Frederic Schäfer, and Wolfgang Maass \\ University of St. Gallen, Switzerland
}

\begin{abstract}
More and more newspaper and magazine Web sites offer paid content. However, selling information goods at a price higher than the marginal cost means finding a strategy for product or price differentiation. A possible strategy to solve this problem is the bundling of information goods.

In this article, we analyze empirically, with quantitative statistic methods, strategies for selling bundled and unbundled content on newspaper and magazine Web sites. This analysis is based on the theoretical approach of Bakos and Brynjolfsson (1996).

The article shows that a cannibalization takes place if the same bundle of information goods is offered in offline (printed) and online (digital) media at the same time. Traditional bundling models work nonetheless in an online media if the online content is rebundled (e.g., as dossiers about a topic), but thereby do not compete with the printed version.
\end{abstract}

For studying the economics of paid content, newspaper and magazine markets are of particular importance and interest, because the convergence of media is very strong in these markets, so the submarkets of online and print are often interrelated (Chyi \& Sylvie, 2000). Many newspaper and magazine publishers reuse the contents of the printed version online. The printed newspaper is offered for a fee; the online content is mostly for free. On account of this, one must consider online and printed newspapers as substitute goods (Chyi \& Sylvie, 1998) involving a potential risk of cannibalization of the printed version. An indicator for such cannibalization is the fact that young people do not subscribe to daily newspapers but substitute information consumption from news or magazine Web sites during work breaks (Glotz \& Meyer-Lucht, 2003).

From a business perspective, various revenue models exist for newspaper and magazine Web sites: advertising, vertical partnerships in e-commerce, paid content, and so on. The most common revenue model is advertising, but combinations of several revenue models are also observable (Chyi \& Sylvie, 2000). The study of Glotz and Meyer-Lucht (2003) shows that converting the business

Address correspondence to Florian Stahl, mcm institute, Blumenbergplatz 9, St. Gallen, Switzerland. E-mail: Florian.Stahl@ unisg.ch model of a newspaper Web site from a freely available content, which is financed through advertising revenues, to a subscription model or paid content is not a successful solution to solve the cannibalization problem. This is true because the decrease of advertising revenues is greater than the increase of revenues through paid content. However, the slump in the online advertising market has forced newspaper Web sites to seek new revenue sources.

To offer paid content as premium content in addition to free and advertised content is one possibility to generate new revenues. Since the beginning of the World Wide Web the debate and discussion about paid content has been very ideological. Articles like "The ROI of free" (Eisenberg, 2002) or scientific contributions like "follow the free" (Loebbecke, 1999) or "Selling More by Giving It All Away Approach” (Zerdick et al., 1999) stress the special importance of free content both from the user and business perspective.

However, the ideological debate about paid content also has an economic background, because selling content online differs from selling content outside the Web as well as from the e-commerce of nondigital products.

In this context, newspaper and magazine Web sites tend more and more to offer bundled information for fees. This phenomenon is well described in the economic literature of bundling of information goods where various 
models exist, explaining why bundling of information goods leads to higher prices and revenues compared to unbundled single articles (Bakos \& Brynjolfsson, 1996; Fay \& MacKie-Mason, 2001; Varian, 2001). Bundling of information goods is a form of price discrimination and a reasonable revenue model, because selling information goods based on traditional economic rules such as price should equal marginal cost do not seem to be feasible in this context (Varian, 2001). Siegel (2002) explained that in the electronic paid content market of news and magazines, single articles are offered more often as complete magazines. On the other hand, scientists like Bakos and Brynjolfsson (1997) conclude that bundling is not always maximizing profit and that in certain circumstances disaggregation leads to higher revenues than bundling. However, low marginal cost facilitates bundling strategies of digital services and goods and thus improves revenues by skimming the willingness to pay of consumers (Siegel, 2002).

In the newspaper and magazine market three main types of paid information goods were identified. The first type of information goods can be classified as bundles, which are also offered as printed versions in the traditional newspaper and magazine market. Henceforth this kind of bundle is just called bundle or bundled information. The second type of information goods is a single digital article, which can be bought at a set price (e.g., archive articles). The third type is rebundled information. Rebundled information mostly consists of bundled digital articles, which are offered by a supplier in a specific way (e.g., on specific topics) and thus are only available in the online world (e.g., dossiers at Spiegel online).

We present findings on which of these strategies for the bundling of paid content attracts the highest demand (measured by the number of purchase transactions) and maximizes the revenues of the publishers.

\section{Research Question}

This led to the following research question: Which strategy for bundling and splitting maximizes the demand and the revenues of paid content on newspaper and magazine Web sites? Different strategies for paid content on newspaper and magazine Web sites are analyzed, with a special focus on three different types of information bundling (bundles, single articles, and rebundles). Empirical research has shown that sometimes the revenues and the demand of bundles outperform that of single information goods and sometimes they do not. This phenomenon is examined and explained in this article.

The following section gives an overview about the literature of bundling of information goods. Based on these theories, an approach is derived and tested empirically. In the last section, the impact of the empirical findings on the bundling theories and the implications of these empirical findings are discussed.

\section{Literature Review: Strategies for Bundling}

In this section, an overview of the literature of the bundling of information goods is provided as a basis for empirical research of paid content on newspaper and magazine Web sites. At first glance, three periods in this discussion and citations could be identified (see Figure 1). In the first period, until 1995, bundling was only discussed for certain nonelectronic goods, which had nearly the same characteristics as information goods. Then Varian (1995) and Salinger (1995) discussed bundling in the context of electronically available information goods. Between 1995 and 2000, models from Bakos and Brynjolfsson (1996, 1997, 2000) systematically analyzed why information goods can be sold with higher profits as bundles. From 2000 on, the discussion shifted to analyzing how competition influences bundling strategies of firms that sell information goods. With the advent of paid content on the Web it was possible to apply these theoretical bundling concepts in real-life settings and thus to test them empirically.

If we go back, Schmalensee (1984) was one of the first authors who discussed bundling in a context that fits the characteristics of e-commerce. In his article, he described the phenomenon of heterogeneous buyers' taste in a monopolistic market, where the monopolist produces two goods. He assumed the marginal utility for the second (reproduced) good to be zero for all buyers. In this setting, Schmalensee showed that with a pure bundle of these two goods, sellers can capture the consumer surplus and thus achieve a higher price through price discrimination. Therefore this model fits very well the situation in the online world, where consumers of information goods in the electronic media have heterogeneous preferences and marginal costs of reproduction are near zero.

Salinger (1995) enriched the model of Schmalensee (1984) by showing how the correlation of customers' demands influences the incentive to bundle. Given the assumption that bundling does not affect costs, negative correlated reservation values and low component costs create an incentive to bundle, because reservation value of customers will converge. If, in addition to that, marginal costs of the elements of the bundle are below this reservation value, the seller of the bundle can extract a surplus. These characteristics described by Salinger fit to information goods sold in the electronic media almost perfectly.

Varian (1995) discussed various forms of price discrimination by market segmentation in low-demand and 


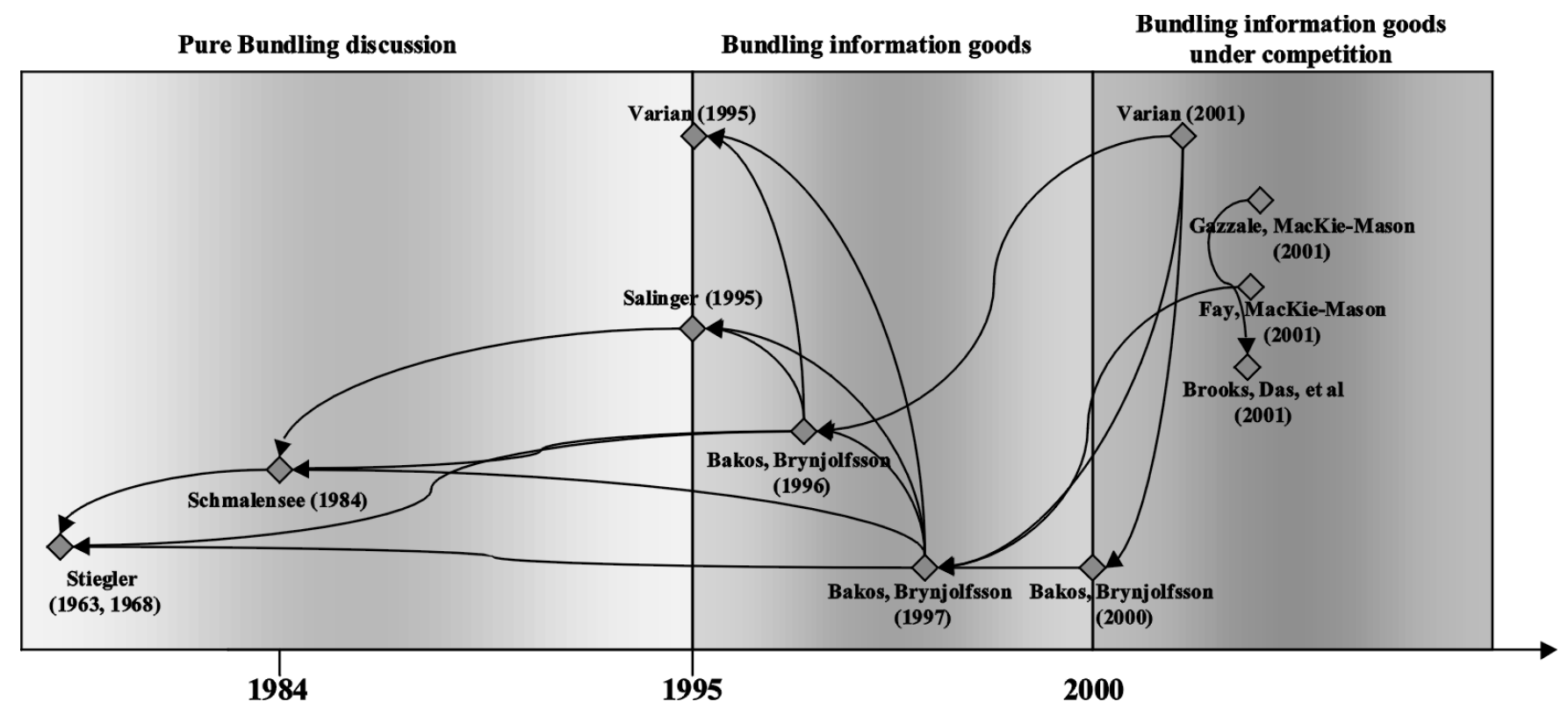

Figure I. The models from Schmalensee (I 984) to Gazzale and MacKie-Mason (200I).

high-demand sectors through product differentiation. In this article he also mentions that bundling can be profitable through the reduction of the heterogeneity of the customers' willingness to pay. Besides this effect, he identifies various other effects like reduction of searching costs if the bundled articles are on similar topics.

Bakos and Brynjolfsson (1996) analyzed optimal strategies for a monopolist offering multiple products and showed that the profit and consumer valuation of large bundles dominates small bundles of information goods. They found that bundling a large number of unrelated information goods could be surprisingly profitable. In their approach, they considered

a setting with a single seller providing $n$ information goods to a set of consumers $\Omega$. Each consumer can consume either 0 or 1 unit of each information good, and resale is not permitted (or is unprofitable for consumers). For each consumer $\omega \in \mathrm{W}$, let $v_{n i}(\omega)$ denote the valuation of good $i$, when a total of $\mathrm{n}$ goods are purchased. (Bakos \& Brynjolfsson, 1996, p. 3f)

The valuation of good $i$ further depends on the number of goods purchased $n$, so that distribution of valuations for individual goods changes with $n$. The per-good valuation of the bundle can be described with

$$
x_{n}=\frac{1}{n} \sum_{k=1}^{n} v_{n k}
$$

Bakos and Brynjolfsson (1996) assumed that the following conditions hold:

A1: The marginal cost of copies of all information goods is zero to the seller.

A2: For all $n$, consumer valuations $v_{n i}$ are independent and uniformly bound, with continuous density functions, nonnegative support, mean $\mu_{n i}$ and variance $\sigma^{2}{ }_{n i}$.

A3: Consumers have free disposal. In particular, for all $n>1$,

$$
\sum_{k=1}^{n} v_{n k} \geq \sum_{k=1}^{n-1} v(n-1) k
$$

If A1, A2, and A3 hold, selling a bundle of all information goods $n$ can be remarkably superior to selling goods separately; the profit of bundling grows, and the bigger the bundle is because "as $n$ increases, the seller captures an increasing fraction of the total area under the demand curve, correspondingly reducing both the deadweight loss and the consumer surplus related to selling the goods separately."

By introducing marginal, transaction, and distribution costs, Bakos and Brynjolfsson (1997) showed that constellations exist where bundling dominates unbundled sales and vice versa, as well as where both forms of sales can be unprofitable. However, in contrast to their model, in practice, firms like the FIRSTGATE Internet $A G$ offer technologies for micropayment, which 
are widely used to sell single information goods at negligible transaction costs.

By another extension of their model, Bakos and Brynjolfsson (2000) showed a nonmonopolistic environment of competition for information goods. In the first case, they analyzed upstream competition: That means sellers of information goods compete for inputs they can sell. In this context, rivals try to bid in a strategic race for the largest bundle, which is similar to traditional economies of scale markets. In the second case they analyzed downstream competition: That means sellers compete for customers in the same market of information goods. Bakos and Brynjolfsson (2000) showed that in competition benefits of bundling are lower than in a monopolistic market but higher than marginal cost.

Varian (2001) mentioned another effect of bundling. Suppliers of information goods can effectively use bundling to hinder new competitors from entering the market, because most attractive buyers are already taken.

A new aspect of information bundling was introduced by Brooks et al. (2001). In their model they took a closer look at the development of bundles and their price over time. They showed that bundling strategies cannot be considered as a steady state but have to change over time to maximize profit. Constant learning and readjustment of bundles allow suppliers to gain the highest profit. This simple model is tested by some experiments.

Fay and MacKie-Mason (2001) showed in their approach that competition between two firms selling information goods lowers prices significantly, whereas the reduction of profits is only moderate. They mainly analyzed four combinations. On the one hand they compared monopolistic and duopolistic sellers and on the other hand they compared homogenous and heterogeneous consumers. They showed that under certain conditions results gained from a monopolistic model also hold in a duopoly, and competitive bundling leads to more potential readers due to lower fees through this competition between firms.

Gazzale and MacKie-Mason (2001) also analyzed how competition in a market of information goods leads to a firm's choice to either stay in a competitive mass market or enter a less competitive niche market with fewer customers.

\section{Empirical Analysis of Strategies for Selling Paid Content}

The empirical analysis of strategies for selling paid content on newspaper or magazine Web sites is based on theories and approaches for bundling and splitting of information goods presented in the last section.
Bakos and Brynjolfsson (1996) showed in their paper that the profit of bundling grows the bigger a bundle is because

the law of large numbers assures that the distribution for the valuation of the bundle has an increasing fraction of consumers with "moderate" valuations near the mean of the underlying distribution ... the demand curve becomes more elastic near the mean and less elastic away from the mean. (Bakos \& Brynjolfsson, 1996, p. 5)

The reasons for a deadweight loss per good and the consumer surplus per good for a bundle of $n$ information goods converge to zero, and the seller's profit per good is maximized.

Empirical evidence for Bakos and Brynjolfsson (1996) is shown for Web sites that offer a bundle of information goods for a single price (printed newspapers or magazines; e.g., a bundle of different articles on different topics or software products like the Microsoft operating system, a bundle of different software programs developed by other firms and previously sold separately). However, there also exists empirical evidence that challenges the model of Bakos and Brynjolfsson. Web sites of printed newspapers and magazines offer digital content in the form of single articles (often in the archive) - they do not offer bundles of information goods (like a digital version of the newspaper or the magazine). Examples are the New York Times (http://www.nytimes.com/) or The Economist (http://www.economist.com). This implies that the model of Bakos and Brynjolfsson, especially Assumption A3, does not work for all kinds of information goods.

Based on these observations the demand and the revenues of paid content is analyzed by different strategies of bundling and splitting. The goal of this empirical analysis is on the one hand to review the theories of Bakos and Brynjolfsson $(1996,1997)$ and on the other hand to show which strategy optimizes the demand and the revenues of paid content on newspaper and magazine Web sites. In the empirical analysis, three types of bundles are included: the same information bundle offered online (digital) and offline (printed), single articles, and rebundled information goods (e.g., as dossiers on a distinct topic). In the following section we show the empirical relation between offline (printed) bundles sold online, single articles, and rebundled article collections.

\section{Data}

The strategies for bundling paid content of newspaper or magazine Web sites were tested on a set of data from the German micropayment provider FIRSTGATE Internet AG. FIRSTGATE Internet AG is the leading micropayment provider in Germany with 2,500 suppliers of paid content 
Table I. List of Analyzed Newspaper and Magazine Web Sites

\begin{tabular}{lccc}
\hline & $\begin{array}{c}\text { Same Bundle } \\
\text { of Information } \\
\text { as the Printed } \\
\text { Bundle }\end{array}$ & $\begin{array}{c}\text { Unbundled } \\
\text { Single } \\
\text { Articles }\end{array}$ & $\begin{array}{c}\text { Rebundled, } \\
\text { New } \\
\text { Combinations } \\
\text { of Articles }\end{array}$ \\
\hline capital.de & & $\mathrm{X}$ & $\mathrm{X}$ \\
FAZ.net & $\mathrm{X}$ & $\mathrm{X}$ & $\mathrm{X}$ \\
$\begin{array}{l}\text { Financial Times } \\
\text { Deutschland }\end{array}$ & $\mathrm{X}$ & $\mathrm{X}$ & $\mathrm{X}$ \\
$\begin{array}{l}\text { Focus online } \\
\text { heise online } \\
\text { manager magazine }\end{array}$ & & $\mathrm{X}$ & $\mathrm{X}$ \\
Harvard \\
$\quad \mathrm{Businessmanager}$ & & $\mathrm{X}$ & $\mathrm{X}$ \\
$\quad \begin{array}{l}\text { Deutschland } \\
\text { PC-WELT }\end{array}$ & & $\mathrm{X}$ & \\
SPIEGEL ONLINE & $\mathrm{X}$ & $\mathrm{X}$ & $\mathrm{X}$ \\
WELT.de & $\mathrm{X}$ & & $\mathrm{X}$ \\
\hline
\end{tabular}

and paid services and 2.5 million registered users. The data set of the seller contains ID, seller name, the Web sites with uniform resource locator, and the different prices of the offered goods stored.

For the empirical analysis a subsample of 10 newspaper and magazine suppliers was drawn. The criterion of extraction was the following: Each supplier offering bundled information offline (in the form of a printed newspaper or magazine) and aggregated or disaggregated paid content online was extracted. The sample of these 10 newspaper and magazine suppliers and the type of bundling and splitting of information goods is listed in Table 1. This sample includes 91,456 purchase transaction from 48,264 customers in the period from October 2003 to December 2003 (all purchase transactions of the suppliers in this period). In addition, the number of page visits to the Web sites of these suppliers was added to the data set. Page visits were used for standardization and scaling, allowing the comparison of sellers with different market share and media coverage.

First, the revenues of suppliers were assigned to the three types of information bundles (bundle, single article, rebundle). In a second step, the number of purchase transactions and the sum of revenues were assigned to each type of information bundle by month and supplier. To gain comparable data the results were scaled by the number of purchase transactions and the revenues were scaled per million visits for each supplier, type of information bundle, and month.

\section{Methodology and Results}

The analysis of the data was performed in three steps. First, average transaction volume and revenues per type of information bundling were computed (bundling, single document, and rebundling). Second, the correlation between the type of bundling and revenues, in the form of the number of purchase transactions per million visits, was analyzed. Third, the significance of results from Step 1 and 2 was analyzed by computing an analysis of variance (ANOVA). To show the relation among the three types of information bundles empirically, Table 1 presents the means of transaction volume and the revenues per million visits.

The results in Table 2 show that suppliers offering the same bundle of information goods online and offline achieve only $46 \%$ of the revenues per million visits compared to suppliers who offer their information goods in unbundled or disaggregated form, compared with rebundled information goods, for which the revenues per million visits account only for $8 \%$.

If we compare the difference in transaction volume per million visits between same bundle of information goods and unbundled single articles with the difference between same bundle of information goods and rebundled information goods, we can identify nearly the same ratio.

These statistics provide a first indication that bundles that are offered offline (printed) and online (digital) at the same time are outperformed by single (digital) articles, which are in turn outperformed by rebundled (digital) articles.

The statistics in Table 2 do not show if this conclusion holds if sellers provide more than one type of bundle of information goods. Therefore correlation between revenues and purchase transaction for sellers offering several types of bundles at the same time is analyzed. The correlation coefficient between the revenues per million visits of suppliers selling their content both as a bundle of information goods and as single information goods is .5763; the covariance is 27.1009 . The positive correlation shows that the difference in purchase transactions and revenues is due to the type of information goods provided. This means that there is a strong positive correlation between revenues and the kind of bundling type if sellers offer their content unbundled.

Table 2. Revenue and Number of Purchase Transactions per Million Visits for Each Kind of Selling Paid Content Online

\begin{tabular}{lcc}
\hline $\begin{array}{l}\text { Kind of Selling Paid } \\
\text { Content }\end{array}$ & $\begin{array}{c}\text { Revenue per } \\
\text { Million } \\
\text { Visits (in } € \text { ) }\end{array}$ & $\begin{array}{c}\text { Number of Purchase } \\
\text { Transactions per } \\
\text { Million Visits }\end{array}$ \\
\hline $\begin{array}{l}\text { Same bundle of } \\
\text { information as the } \\
\text { printed bundle }\end{array}$ & 69.94 & 35.32952 \\
$\begin{array}{l}\text { Unbundled single articles } \\
\text { Rebundled, new } \\
\text { combinations of articles }\end{array}$ & 149.92 & 173.9007 \\
& 839.51 & 173.3987 \\
\hline
\end{tabular}


Table 3. Correlation Coefficient and Covariance

\begin{tabular}{|c|c|c|c|c|}
\hline \multirow[b]{2}{*}{ Kind of Selling Paid Content } & \multicolumn{2}{|c|}{ Revenue per Million Visits } & \multicolumn{2}{|c|}{$\begin{array}{c}\text { Number of Purchase Transactions } \\
\text { per Million Visits }\end{array}$} \\
\hline & Correlation Coefficient & Covariance & Correlation Coefficient & Covariance \\
\hline $\begin{array}{l}\text { Same bundle of information as the printed } \\
\text { bundle and unbundled single articles }\end{array}$ & .5763 & 27.1009 & .6295 & 33.5252 \\
\hline $\begin{array}{l}\text { Unbundled single articles and rebundled, new } \\
\text { combination of articles }\end{array}$ & .3998 & 171.115 & -.2177 & -10.9613 \\
\hline
\end{tabular}

Table 4. Transaction Volume in Relation to the Type of Bundling

\begin{tabular}{lcccr}
\hline Source & Partial SS & df & MS & $F$ \\
\hline Model & 1074183.19 & 2 & 537091.595 & 44.72 \\
Bundling type & 1074183.19 & 2 & 537091.595 & .0002 \\
Residual & 72056.056 & 76 & 12009.3427 & .0002 \\
Total & 1146239.25 & 80 & 143279.906 & \\
\hline
\end{tabular}

Note. $N=81$. Root MSE $=109.587 . R^{2}=.9371$. Adjusted $R^{2}=.9162$.

Table 5. Revenues in Relation With Type of Bundling

\begin{tabular}{lcccr}
\hline Source & Partial SS & df & MS & $F$ \\
\hline Model & 38265.3156 & 2 & 19132.6578 & 479.59 \\
Bundling type & 38265.3156 & 2 & 19132.6578 & 479.59 \\
Residual & 239.362651 & 76 & 39.8937751 & .0000 \\
Total & 38504.6783 & 80 & 4813.08479 & .0000 \\
\hline
\end{tabular}

Note. $N=81$. Root MSE $=6.31615 . R^{2}=.9938$. Adjusted $R^{2}=0.9917$.

The correlation coefficient between the revenues per million visits of suppliers selling their content both as unbundled single articles and as rebundled, new combinations of articles is .3998 and has a covariance of 171.115.

As displayed in Table 3, correlation between the bundle of information goods and single articles measured in transaction volume per million visits is strongly positive (.6295), but in the second case, where suppliers offer both unbundled single articles and rebundled information goods, we find a negative correlation (-.2177). This means rebundling of articles helps to raise the revenues but lowers the number of purchase transactions.

The means of revenues and purchase transactions per million visits and the correlation coefficient indicate a strong relation to the kind of bundling and splitting. To analyze the significance of this relation, an ANOVA was computed. The ANOVA is a method that analyzes the effect of one or several independent variables (e.g., the kind of bundling or splitting) in relation to one dependent variable (e.g., revenues or transaction volume per million visits; Backhaus, Erichson, \& Plinke, 2003). To analyze the impact of aggregation and disaggregation on each of the dependent variables (revenues and transaction volume per million visits) a one-way ANOVA was computed.
As shown in Table 4, a highly significant influence of the type of bundling on the transaction volume can be identified. With a $99 \%$ confidence interval a Prob $>F$ value of .0002 is found, which is an indicator for very high significance.

In Table 5 an even more significant influence of the type of bundling on the revenues can be identified. With 99\% confidence interval a Prob $>F$ value of .0000 and an $F$ value of 479.59 were computed. This shows that the results in Steps 1 and 2 are significant.

These statistics fully support the conclusion that single articles in terms of purchase transactions and revenues outperform offline (printed) bundles sold online and that single articles are outperformed by revenues, but not by transaction volume of rebundled article bundles.

\section{Discussion and Implications}

The previous section showed that the same information bundle offered online (digital) and offline (printed) generates nearly no demand in the online world and therefore the valuations (measured revenues and purchase transac- 
tions) are higher for single articles. If these single information goods are rebundled, the valuation of this bundle is much higher.

To explain the phenomenon that in the online newspaper and magazine market some bundles are outperformed in revenues and transaction volume by single articles and single articles are outperformed by other bundles, we make a proposition in addition to the three assumptions of Bakos and Brynjolfsson (1997).

Under the proposition of Bakos and Brynjolfson (1996), if the same bundle of information goods is provided offline (printed) and online (digital), customers prefer the offline bundle, so we can conclude that the valuation of a printed bundle $v_{p}$ sold in the offline world is outperformed by the valuation $v_{i}$ of any single digital article $i$ in the online world. On the other hand, the valuation of any bundle $v_{d}$, where $d \neq p$ outperforms a single article $i$ sold online (Bakos \& Brynjolfsson, 1997). Therefore we can conclude in the competition of information goods that the relation between valuation $v$ is the following:

$$
v_{p}<v_{i}<v_{d}
$$

where $p=$ digital version of a printed information bundle, $i=$ single digital article, $d=$ digital bundle of articles, and $d \neq p$.

The empirical analysis shows that existing theoretical approaches and models in the bundling literature do not explain all aspects of bundling information goods because they take into consideration only one medium as the distribution channel. The implication of these findings is that a printed bundle of newspaper and magazine content must be split or rebundled on the Web so that a demand for this content exists.

These findings indicate that there is competition between offline and online newspapers, but not in the way Chyi and Sylvie (2000) identified it. Online newspapers may compete with their offline versions and influence their sales volume. However, if we look at it another way, offline newspapers are a strong competitor for online newspapers and magazines as well. In addition to Chyi and Sylvie (1998) showing the cannibalization of printed versions of information bundles, it has been shown in this article that the cannibalization problem also exists for digital information goods through the printed information bundles. Therefore online newspapers have to differentiate information goods against the offline versions by selling single articles or using the potential of rebundling in electronic media. Under this aspect the convergence of online and offline newspapers has to be further analyzed from the online perspective, which suffers strong competition from the offline world. As several newspaper and magazine Web sites show by offering dossiers on specific topics, such a convergence of media can be used to produce complementary goods, raising the benefits of both sectors (the online and the offline sectors).

Practical implications of the empirical findings presented in this article are that the same information bundle cannot be sold in two or more different media at the same time if there exists a well-established habit to consume this content. These habits can change through digital media (Palmer \& Eriksen, 1999). Therefore the business models of traditional newspaper and magazine markets cannot be transferred one-to-one to the online world without product differentiation. Possible alternatives of product differentiation are splitting of the information bundle supplied in the printed version of the newspaper or magazine on the Web or rebundling it into new digital information goods.

\section{Conclusions}

In this article it is shown that bundling theories, especially the approach of Bakos and Brynjolfsson (1996), seem to work within a single medium and that the revenues of rebundled information goods outperform the online revenues of split newspaper or magazine articles. However, in addition to their approach, we show that their approach has to be extended if information bundles are offered in various media at the same time. A conclusion that can be derived from the findings in this article is that the revenues of paid content on newspaper or magazine Web sites are higher if information is rebundled (e.g., as dossiers) and not sold as single articles (e.g., in the archive of the Web site) or as bundles that are identical to the printed version.

Of course further research has to be done in this area to analyze the competition and complementary effects of the convergence of the offline and the online world. Only a look at newspapers and magazines with a broad range of topics has been given. Therefore it is possible that the identified correlations are not observable for magazines with a very specific focus (e.g., magazines for handymen or magazines about cars).

Whether these findings can be extended to other media sectors and markets has to be analyzed. It is not clear yet if these strategies for bundling and splitting are also applicable to, for example, the music market and if thus music CDs would achieve higher revenues when sold disaggregated or rebundled on online media. However, the existence of rebundled compilations with different artists in addition to albums of a single artist and the high demand for single music files on online music stores as MyCokeMusic.com or the Apple iTunes music store (http:// www.apple.com/itunes/) give a first idea that the findings presented in this article might also be relevant in other media sectors. 


\section{Florian Stahl \\ (florian.stahl@unisg.ch)}

is a Research Assistant at the mcm institute, University of St. Gallen, Switzerland. His research focuses on the economics of paid content and the interrelation of product and price differentiation of digital goods.

\section{Marc-Frédéric Schäfer \\ (marc-frederic.schaefer@gmx.de)}

is a Research Assistant and PhD student at the mcm institute, University of St. Gallen, Switzerland. He studied economics with a major in finance at University of St. Gallen, Switzerland, and at HEC Paris, France, and holds a degree from University of St. Gallen, where he finished his master's studies in October 2002. Prior to joining the mcm institute, Marc-Frédéric worked for the mcm institute as a programmer, IBM Consulting Group in Zürich, Switzerland, and the Landesbank Baden-Württemburg in Stuttgart, Germany.

\section{Wolfgang Maass}

(wmaass@acm.org)

is a senior researcher at the mcm institute, University of St. Gallen, Switzerland. He studied computer science at the University of Aachen (RWTH) and at the University of Saarbrücken. His doctoral studies have been in the domain of cognitive science. He worked at the German Research Center for Artificial Intelligence (DFKI) and the National Center for Geographic Information and Analysis (NCGIA), UCSB.

\section{References}

Backhaus, K., Erichson, B., \& Plinke, W. (2003). Multivariate Analysemethoden [Multivariate methods of data analysis]. Berlin: Springer Verlag.

Bakos, Y., \& Brynjolfsson, E. (1996). Bundling information goods: Pricing, profits and efficiency. Retrieved January 1, 2004, from http:/l papers.ssrn.com/sol3/Delivery.cfm/98111102.pdf?abstractid= 11488

Bakos, Y., \& Brynjolfsson, E. (1997). Aggregation and disaggregation of information goods: Implications for bundling, site licensing and micropayment. In B. K. D. Hurley \& H. Varian (Eds.), Internet publishing and beyond: The economics of digital information (pp. 114-137). Cambridge, MA: MIT Press.
Bakos, Y., \& Brynjolfsson, E. (2000). Bundling and competition on the Internet. Marketing Science, 19(1), 63-82.

Brooks, C. H., Das, R., Kephart, J. O., MacKie-Mason, J. K., Gazzale, R. S., \& Durfee, E. H. (2001, October). Information bundling in a dynamic environment. Paper presented at the Third ACM Conference on Electronic Commerce, Tampa, FL, USA.

Chyi, H. I., \& Sylvie, G. (1998). Competing with whom? Where? And how? A structural analysis of the electronic newspaper market. The Journal of Media Economics, 11(2), 1-18.

Chyi, H. I., \& Sylvie, G. (2000). Online newspapers in the U.S. International Journal on Media Management, 2(2), 69-77.

Eisenberg, B. (2002). The ROI of free. Retrieved January 10, 2004, from http://www.clickz.com/experts/design/traffic/article.php/ 1368441

Fay, S. A., \& MacKie-Mason, J. K. (2001). Competition between firms that bundle information goods. Retrieved January 18, 2004, from wwwpersonal.umich.edu/ jmm/courses/ econ731/bundle-13nov98.pdf

Gazzale, R. S., \& MacKie-Mason, J. K. (2001, October). Endogenous differentiation of information goods under uncertainty. Paper presented at the EC'01, Tampa, FL.

Glotz, P., \& Meyer-Lucht, R. (2003). Zeitung und Zeitschrift in der digitalen Ökonomie - Delphi-Studie [Newspapers and magazines in the digital economy]. Retrieved from http:/|www.unisg.ch/org/ $\mathrm{mcm} /$ web.nsf/forum?openpage

Loebbecke, C. (1999, June). Electronic publishing: Investigating a new reference frontier, global networked organzations. Paper presented at the Twelfth Bled Electronic Commerce Conference, Bled, Slovenia.

Palmer, J. W., \& Eriksen, L. (1999). Digital news: Paper, broadcast and more converge on the Internet. International Journal on $\mathrm{Me}$ dia Management, 1(1), 31-34.

Salinger, M. A. (1995). A graphical analysis of bundling. The Journal of Business, 68(1), 85-98.

Schmalensee, R. (1984). Gaussian demand and commodity bundling. The Journal of Business, 57(1), 211-230.

Siegel, F. (2002). Preisfindung für den Vertrieb digitaler Dienstleistungen und Güter [Pricing for sales of digital services and goods]. In Proceedings of LIT 2002. Leipzig, Germany.

Varian, H. R. (1995, May). Pricing information goods. Paper presented at the Proceedings of Scholarship in the New Information Environment Symposium, Harvard Law School, Cambridge, MA.

Varian, H. R. (2001). Economics of information technology. Retrieved April 23, 2003, from www.sims.berkeley.edu/ $\sim$ hal/Papers/ mattioli/mattioli.pdf

Zerdick, A., Picot, A., Scharpe, K., Artope, A., Goldhammer, K., Lange, U. T., et al. (1999). Die Internet-Ökonomie. Strategien für die digitale Wirtschaft [The Internet economy: Strategies for the digital economy] (3rd ed.). Heidelberg, Germany: Springer. 